02

\title{
Химически синтезированные частицы золота и серебра, поглощающие в ближней ИК области спектра
}

\author{
(C) Ю.А. Разумова ${ }^{1}$, Н.А. Торопов ${ }^{1,2}$, Т.А. Вартанян ${ }^{1}$ \\ ${ }^{1}$ Университет ИТМО, \\ 197101 Санкт-Петербург, Россия \\ ${ }^{2}$ Aston University, \\ B4 7ET Birmingham, United Kingdom \\ e-mail: nikita.a.toropov@gmail.com
}

Поступила в редакцию 17.01.2018 г.

\begin{abstract}
Предложены методики создания частиц золота в виде сфер субмикронного размера и частиц серебра в виде стержней с поперечными размерами $\sim 10 \mathrm{~nm}$ и аспектным отношением $1: 10$. Рассмотрены факторы, определяющие частоту плазмонных резонансов, подобраны реагенты и определены их соотношения для получения вытянутых серебряных частиц. Определена оптимальная концентрация поверхностно-активного вещества для создания наиболее вытянутых частиц серебра. Получено смещение плазмонного поглощения в ближнюю ИК область спектра.
\end{abstract}

DOI: $10.21883 /$ OS.2018.05.45950.13-18

\section{Введение}

Наночастицы благородных металлов демонстрируют плазмонные резонансы, обусловленные колебаниями свободных электронов. Частота этих колебаний зависит от материала, геометрических параметров наночастиц и диэлектрической проницаемости окружающего вещества [1]. В настоящее время наиболее распространенными плазмонными материалами являются щелочные и благородные металлы [2,3]. Частицы таких металлов обычно имеют интенсивные полосы поглощения в ультрафиолетовой и видимой областях спектра. В то же время свойства данных структур, проявляющиеся в сильной локализации электрических полей и, как следствие, модификации оптических свойств различных органических и биологических молекул, а также квантовых точек, помещенных в их окрестности, могли бы стать основой для наблюдения новых явлений и в инфракрасной области. К таким свойствам относятся усиление поглощения, возможность наблюдения гигантского комбинационного рассеяния, модификация скорости излучательных и безызлучательных переходов в молекулах и квантовых точках и другие [4-8].

Для продвижения в инфракрасный диапазон в последнее время активно ведутся исследования оптических свойств новых плазмонных материалов. В частности, было предложено использовать коллоидные квантовые точки на основе халькогенидов металлов с нарушенным стехиометрическим соотношением $[9,10]$. Однако огромный интерес к ближней инфракрасной области обусловлен не только возможностью наблюдения фундаментальных закономерностей, но и для решения ряда прикладных задач. Во-первых, так как многие биоткани имеют окна прозрачности в ближнем инфракрасном диапазоне спектра, наночастицы благородных металлов можно применять в задачах биомедицины. Во-вторых, основные телекоммуникационные длины волн лежат в ближней инфракрасной области спектра, что, в свою очередь, обусловлено окнами прозрачности кварцевых волоконно-оптических линий связи. Плазмонные эффекты помогли бы улучшить характеристики оптоэлектронных устройств. Предложенные квантовые точки, имеющие плазмонные резонансы в ближней ИК области, в настоящее время не очень подходят для решения таких задач, поскольку они способны оказывать негативное влияние на живые организмы, а их состав и свойства нестабильны.

Таким образом, целью настоящей работы было создание методов синтеза наночастиц из благородных металлов, плазмонные резонансы которых смещены в красную область спектра относительно резонансов сферических частиц в водной среде.

\section{Теоретические предпосылки, материалы и методы}

В качестве теоретических предпосылок предлагается рассмотреть известную модель наночастиц в виде наносферы, помещенной в квазистационарное электрическое поле [1]. Плазмонные колебания, возникающие в таких частицах, могут иметь три взаимно ортогональные моды. Однако в модели сферы эти моды трехкратно вырождены и для случая довольно малых $(\sim 10 \mathrm{~nm})$ серебряных частиц в вакууме, используя оптические константы [11], можно вычислить соответствующую им длину волны плазмонного резонанса. В случае одиночной серебряной частицы в вакууме она составляет менее $400 \mathrm{~nm}$. Помимо геометрических характеристик частицы, существенное влияние на частоту плазмонов оказывает диэлектрическая проницаемость окружающего вещества [1]. В случае водных растворов частота 
плазмонных колебаний сферических серебряных частиц диаметром $\sim 10 \mathrm{~nm}$ соответствует $405-410 \mathrm{~nm}$. Соответственно при контакте со средой с более высокой действительной частью диэлектрической проницаемости, например с арсенидом галлия, длина волны составит большие величины [12].

Переходя к модели частицы в виде вытянутого сфероида, можно показать, что частота плазмонных колебаний, соответствующая большей полуоси сфероида, уменьшается. Так, при использовании сильно вытянутых частиц, например, с аспектным отношением полуосей $1: 10$, длина волны соответствующих плазмонных резонансов составляет почти $1000 \mathrm{~nm}$ [1]. Отметим, что дипольные плазмонные осцилляции в частицах серебра и золота возбуждаются при взаимодействии со светом, половина длины волны которого больше размера частиц. Если длина волны становится сопоставимой с размером частицы, то могут наблюдаться квадрупольные осцилляции $[1,13]$, а также, потенциально, осцилляции более высоких порядков.

В настоящей работе для изменения частоты плазмонных резонансов варьируется геометрия частиц. В первом случае были синтезированы коллоидные растворы сферических золотых частиц субмикронных размеров, во втором - серебряных частиц в виде вытянутых сфероидов.

Для создания обоих растворов был использован метод опосредованного роста зародышей, при котором смешиваются два основных компонента. Первый компонент затравочный раствор, содержащий наночастицы золота или серебра размером $1-10 \mathrm{~nm}$ в стадии нуклеации. Второй компонент смеси обеспечивает дальнейший рост более крупных частиц в случае золота, либо анизотропные условия роста в случае серебряных стержней.

Частицы золота были сформированы из затравочного раствора, приготовленного на основе золотохлористоводородной кислоты $\left(\mathrm{HAuCl}_{4}\right)$ объемом $5 \mathrm{ml}$ (концентрация $0.5 \mathrm{mmol} / \mathrm{l}$ ). Для обеспечения нуклеации частиц в затравочном растворе было использовано поверхностно-активное вещество цетилтриметиламмоний бромид (СТАВ), растворенный в $5 \mathrm{ml}$ деионизованной воды с помощью ультразвуковой ванны (концентрация $25 \mathrm{mmol} / \mathrm{l})$, а также $0.6 \mathrm{ml}$ боргидрида натрия $(10 \mathrm{mmol} / \mathrm{l})$, добавлявшегося охлажденным до $0^{\circ} \mathrm{C}$. Для роста частиц $25 \mu \mathrm{m}$ затравочного раствора добавлялось в предварительно подготовленный ростовой раствор. Состав ростового раствора: $10 \mathrm{ml}$ CTAB (30 mmol/1) активно смешивались с $0.25 \mathrm{ml}$ нитрата серебра (4 mmol/l), к ним добавлялось $5 \mathrm{ml} \mathrm{HAuCl} 4(1 \mathrm{mmol} / \mathrm{l})$. После аккуратного перемешивания добавлялось $70 \mu 1$ аскорбиновой кислоты $(0.8 \mathrm{~mol} / \mathrm{l})$. При добавлении затравочного раствора и в течение следующих $30 \mathrm{~min}$ ростовой раствор поддерживался при комнатной температуре и не перемешивался.

Полученные коллоидные растворы исследовались в кюветах методом абсорбционной спектроскопии в диапазоне длин волн 200-900 nm, а также наносились на полупроводниковые подложки арсенида галлия и исследовались с помощью сканирующей электронной микроскопии (Zeiss Merlin) в режиме обратного рассеяния электронов.

Для синтеза наностержней серебра были апробированы два подхода. Первый из них, следуя работе [14], использует бинарную смесь поверхностно-активных веществ в ростовом растворе, второй - только СТАВ. Затравочный раствор в обоих случаях состоял из нитрата серебра $(20 \mathrm{ml}$, концентрация $0.25 \mathrm{mmol} / 1)$, восстановленного цитратом натрия $(0.25 \mathrm{mmol})$, и боргидрида натрия. В ходе экспериментов было установлено, что затравочный раствор созревает при комнатной температуре в течение $2 \mathrm{~h}$. По истечении $5 \mathrm{~h}$ затравочный раствор становится непригодным, поскольку частицы переходят в стабильную фазу и дальнейший рост на них не наблюдался.

Ростовой раствор при первом подходе - в случае двухкомпонентной смеси - состоял из СТАВ, смешанного с бензилдиметилгексадециламмоний хлоридом (BDAC). К этим веществам были добавлены нитрат серебра, щелочной раствор и аскорбиновая кислота. Рост удлиненных частиц также происходил без перемешивания затравки и ростового раствора. Несмотря на имеющиеся литературные данные по синтезу наностержней по схожей методике [14], спектры оптической плотности демонстрировали большую долю частиц округлой формы с максимумом на $420 \mathrm{~nm}$ и малозаметным плечом в спектре на длине волны $500 \mathrm{~nm}$. При этом изменение соотношения поверхностно-активных веществ в пользу СТАВ приводило к увеличению оптической плотности длинноволнового максимума спектра. Таким образом, показано, что СТАВ является ключевым реагентом для формирования наностержней и во втором подходе использовалось только это вещество.

\section{Результаты и обсуждение}

На рис. 1 показан спектр поглощения синтезированного раствора золотых частиц. Спектр демонстрирует широкую полосу плазмонного поглощения наночастиц золота. Также приведено изображение наночастиц золота, высаженных на подложку из арсенида галлия. Изображение получено на сканирующем электронном микроскопе. Диаметр получившихся частиц достигает $380 \mathrm{~nm}$. Следует отметить, что при высаживании на подложку частицы агрегируют в более крупные кластеры. Поскольку перед измерением спектров поглощения растворы проходили ультразвуковую обработку, то мы полагаем, что концентрация подобных агломератов в них крайне низка и существенного вклада в спектр они не вносят. Тем не менее, следует отметить, что крыло плазмонного поглощения простирается до $700 \mathrm{~nm}$.

Эксперименты по созданию наночастиц серебра показали, что при добавлении затравочного раствора в ростовой, состоящий из одного поверхностно-активного 

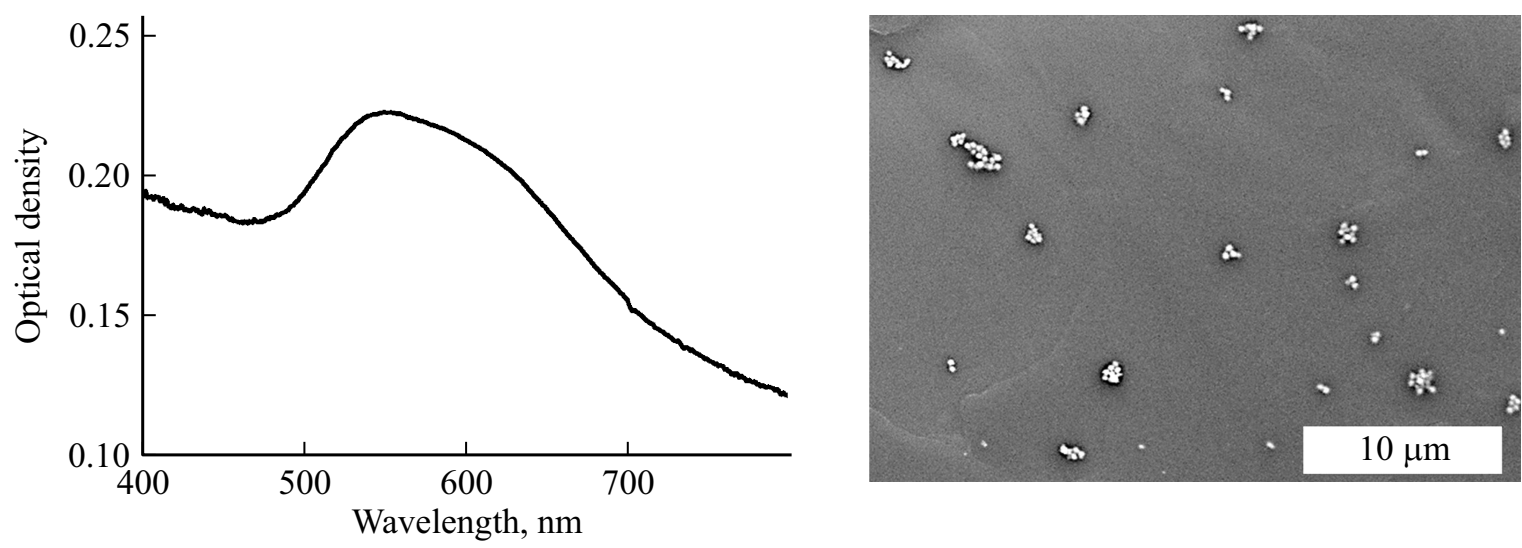

Рис. 1. Спектр поглощения коллоидного раствора синтезированных частиц золота и их СЭМ-изображение.
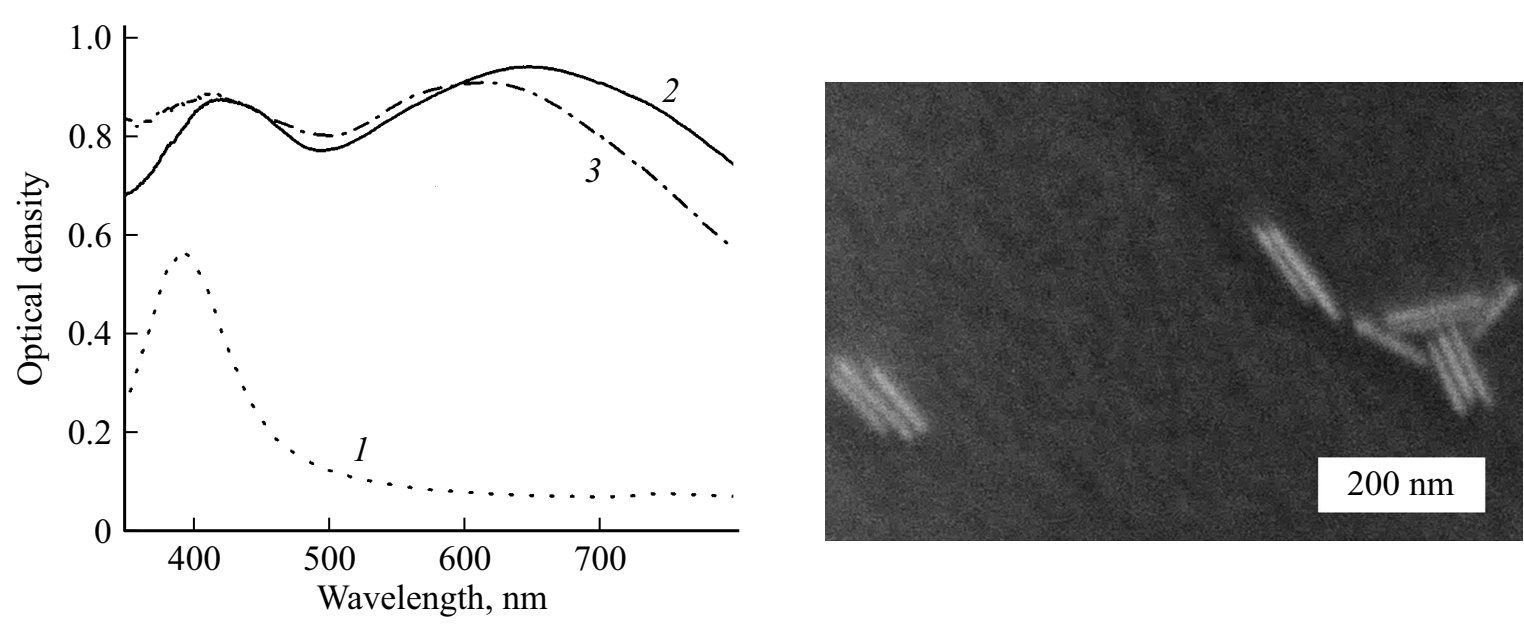

Рис. 2. Спектры поглощения затравочного раствора (1), коллоидного раствора наностержней с содержанием СТАВ 73 mg в ростовом растворе (2) и с содержанием СТАВ $143 \mathrm{mg}$ (3). Справа СЭМ-изображения стержней (73 mg СТАВ) на арсениде галлия.

вещества - СТАВ (10 $\mathrm{ml} \mathrm{c} 73 \mathrm{mg}$ сухого вещества), из нитрата серебра $(0.5 \mathrm{ml}, 100 \mathrm{mmol} / \mathrm{l})$, аскорбиновой кислоты и $\mathrm{NaOH}(0.1 \mathrm{ml}, 1 \mathrm{~mol} / \mathrm{l})$, наблюдалось существенное изменение спектра результирующего раствора по сравнению с раствором-затравкой, состоящего их мелких частиц серебра (рис. 2). При использовании СТАВ наряду с типичным максимумом спектра на $420 \mathrm{~nm}$ проявился максимум оптической плотности на $650 \mathrm{~nm}$, что свидетельствует о формировании наностержней и возбуждении поперечных и продольных плазмонных мод, соответственно.

При этом были исследованы растворы с меньшими и большими концентрациями СТАВ, которые приводили к росту частиц, спектры которых схожи со спектрами затравочного раствора, но более уширены. Либо приводили к смещению полосы плазмонного резонанса в сторону меньших длин волн. Как пример, на рис. 2 показан спектр поглощения коллоида, изготовленного с СТАВ в количестве $143 \mathrm{mg}$ сухого вещества в ростовом растворе.

С помощью сканирующего электронного микроскопа полученные результаты были верифицированы.
На СЭМ-изображении видны серебряные наностержни. Следует отметить, что они не однородны по размерам, что обусловливает большую ширину спектра оптической плотности. Их аспектное отношение достигает 1:10.

\section{Заключение}

Таким образом, в работе показана возможность синтеза наночастиц золота и серебра со смещенными по сравнению со сферическими частицами плазмонными резонансами в красную область спектра. Для серебра показано, что оптимальным с точки зрения создания частиц, поглощающих в ближней инфракрасной области, является использование одного поверхностно-активного вещества - СТАВ. При этом было установлено оптимальное значение его концентрации в ростовом раствоpe. Очевидно, что увеличение аспектного отношения вытянутых частиц возможно при оптимизации концентраций остальных компонентов и условий синтеза, которое будет выполнено нами в будущем. 
Авторы благодарят В.А. Полищука за помощь в проведении СЭМ-исследований; Совет по грантам Президента РФ (МК-228.2017.2), Министерство образования и науки РФ (госзадание 3.4903.2017/6.7) и программу EC Horizon 2020 (713694 MULTIPLY) за финансовую поддержку.

\section{Список литературы}

[1] Kelly K.L., Coronado E., Zhao L., Schatz G.C. // J. Phys. Chem. 2003. V. 107. N 3. P. 668. doi 10.1021/jp026731y

[2] Drampyan R., Leonov N., Vartanyan T. // J.Mod. Opt. 2016. V. 63. N 14. P. 1347. doi 10.1080/09500340.2016.1145747

[3] Toropov N.A., Leonov N.B., Vartanyan T.A. // Phys. Stat. Sol. B. 2018. V. 255. P. 1700174. doi 10.1002/pssb.201700174

[4] Rai V.N., Srivastava A.K., Mucherjee C., Deb S.K. // Appl. Opt. 2012. V. 51. P. 2606. doi 10.1364/AO.51.002606

[5] Kamalieva A.N., Toropov N.A., Vartanyan T.A. // Int. J. Nanotechnology. 2016. V. 13. N 8/9. P. 642. doi 10.1504/IJNT.2016.079667

[6] Kamalieva A., Toropov N., Reznik I., Vartanyan T. // Opt. Quant. Electron. 2016. V. 48. N 12. P. 562. doi 10.1007/s11082-016-0841-2

[7] Nabiullina R.D., Starovoütov A.A., Toropov N.A. // J. Opt. Technol. 2017. V. 84. P. 453. doi 10.1364/JOT.84.000453

[8] Toropov N.A., Starovoytov A.A., Leonov N.B., Kaliteevskaya E.N., Vartanyan T.A. // Proc. SPIE. 2013. V. 8766. P. 87660Q. doi 10.1117/12.2017137

[9] Luther J.M., Jain P.K., Ewers T., Alivisatos A.P. // Nat. Mater. 2011. V. 10. P. $361-366$. doi $10.1038 /$ nmat3004

[10] Balitskii O.A., Sytnyk M., Stangl J., Primetzhofer D., Groiss H., Heiss W. // ACS Appl. Mater. Interfaces. 2014. V. 6. P. 17770-17775. doi 10.1021/am504296y

[11] Johnson P.B., Christy R.W. // Phys. Rev. B. 1972. V. 6. P. 4370. doi 10.1103/PhysRevB.6.4370

[12] Kosarev A., Chaldyshev V., Toropov N., Gladskikh I., Gladskikh P., Baryshnikova K., Preobrazhenskiy V., Putyato M., Semyagin B., Vartanyan T. // Proc. SPIE. 2017. V. 10346. P. 1034613. doi 10.1117/12.2272994

[13] Toropov N.A., Gladskikh I.A., Parfenov P.S., Vartanyan T.A. // Opt. Quant. Electron. 2017. V. 49. N 4. P. 154. doi 10.1007/s11082-017-0996-5

[14] Shajari D., Bahari A., Gill P., Mohseni M. // Opt. Mater. 2017. V. 64. P. 376. doi 10.1016/j.optmat.2017.01.004 